\title{
Ação da laserterapia no processo de proliferação e diferenciação celular. Revisão da literatura
}

\section{Low intensity laser therapy effects on cell proliferation and differentiation. Review of the literature}

Águida Cristina Gomes Henriques'; Claudia Cazal ${ }^{2}$; Jurema Freire Lisboa de Castro 3

R E S U M O

O uso da luz laser de baixa intensidade vem sendo utilizado como terapia coadjuvante ou de forma terapêutica isolada em várias especialidades odontológicas. Suas principais indicações incluem ação anti-inflamatória, analgésica e indutora da reparação tecidual. O poder cicatrizante do laser de baixa potência é discutido neste trabalho assim como os mecanismos de biomodulação e estimulação da mitose. Estas propriedades, já estudadas em células benignas, quando aplicadas em células neoplásicas malignas, abrem espaço para discussões. O objetivo do presente trabalho foi realizar uma revisão da literatura sobre os aspectos indutivos do laser no processo de proliferação celular principalmente no que se refere a estes mecanismos em células neoplásicas malignas.

Descritores: Terapia a laser. Proliferação de células. Terapia a laser de baixa intensidade. Cicatrização de feridas.

\section{INTRODUÇÃO}

A luz do raio laser é um tipo particular de radiação eletromagnética, que apresenta propriedades bem específicas se diferenciando da luz emitida por fontes convencionais incandescentes, o que torna seu uso viável em múltiplas aplicações médicas.

As propriedades terapêuticas do laser vêm sendo estudadas desde a proposição da teoria da emissão estimulada por Einstein, 1917, sendo sugerida pela primeira vez em 1957, por dois cientistas americanos, Charles Townes e Arthur Achawlow, tornando-se realidade em 1960, com a construção do primeiro emissor de laser a Rubi por Theodore Maiman ${ }^{1}$.

A laserterapia tem sido usada com muito sucesso na clinica odontológica. A metodologia é simples, baixo custo e pode ser integrada como auxiliar da terapia para tratamentos convencionais ou usada isolada como modo alternativo em algumas patologias. Os efeitos terapêuticos são: anti-inflamatório, analgésico e indutor da reparação tecidual. O aumento substancial no interesse da terapia tem sido notado em círculos científicos, devido ao significante número de resultados satisfatórios².

Apesar de ser uma técnica relativamente nova dentro da Odontologia, especialistas afirmam categoricamente que o laser tem um grande potencial de uso em todas as especialidades odontológicas. Ele tem mostrado ser uma ferramenta muito atrativa sob diversos aspectos, principalmente porque os pacientes têm buscado profissionais que usem técnicas menos invasivas.

No entanto, deve-se ressaltar que, como qualquer nova tecnologia, os aprimoramentos dos equipamentos bem como os achados clínicos e laboratoriais exigem uma atualização constante dos profissionais da área de saúde que utilizam os lasers.

Os lasers terapêuticos ou de baixa potência são utilizados para acelerar os processos reparativos do tecido duro e do tecido mole, devido aos efeitos biomoduladores nas células e tecidos. Eles ativam ou inibem processos fisiológicos, bioquímicos e metabólicos através de efeitos fotofísicos ou fotoquímicos. Esses fenômenos biomodulatórios promovem os efeitos terapêuticos de morfodiferenciação e proliferação celular, neoformação tecidual, revascularização, redução do edema, maior regeneração celular, aumento da microcirculação local e permeabilidade vascular ${ }^{3,4}$.

Considera-se que as células malignas estejam mais susceptíveis ao processo indutor proliferativo, por apresentarem uma cascata de sinalização bastante alterada, além de modificações progressivas do perfil biológico da célula, com alterações de sua capacidade de proliferação, diferenciação, sobrevida e interação com o meio ambiente. Entretanto, os efeitos da laserterapia em tecidos com potencial para malignização e em células malignas ainda são bastante discutidos.

Trabalho realizado na Disciplina de Patologia Oral da Universidade Federal de Pernambuco - UFPE - Recife - PE-BR.

1. Doutoranda em Patologia Oral - UFRN - Natal - RN-BR; 2. Professor Adjunto da Disciplina de Estomatologia - UFPB; 3. Professor Adjunto da Disciplina de Patologia Oral - UFPE- Recife - PE-BR. 
Propõe-se com este trabalho apresentar uma revisão da literatura sobre a capacidade do laser terapêutico em induzir a proliferação, diferenciação celular, principalmente no que se refere a estes mecanismos em células neoplásicas malignas.

\section{MÉTODOS}

Para o presente trabalho foi realizada uma pesquisa bibliográfica, através de artigos científicos publicados em periódicos nacionais e internacionais nos últimos 23 anos, encontrados nos sites da PUBMED e SCIELO (respectivamente www.pubmed.com e www.scielo.com). Os descritores a seguir, utilizados isoladamente e em combinação, foram pesquisados: low-power laser therapy, mitosis, cell proliferation and lasertherapy. Dos artigos encontrados foram selecionados aqueles que se propuseram a avaliar as propriedades biomodulatórias do laser, assim como trabalhos clássicos sobre as propriedades biológicas do laser. Nos artigos selecionados, os autores empregaram métodos de investigação in vitro e in vivo para estudo do laser de baixa intensidade, e outros tipos de laser, comparando seus resultados indutivos entre grupos experimentais e controles.

\section{REVISÃO DA LITERATURA}

A Odontologia, embora tardiamente, demonstrou interesse na utilização terapêutica do laser, antes utilizada apenas nas especialidades médicas cirúrgicas. Em 1965, Sinclair e Knoll adaptaram esta radiação à prática terapêutica e nesse mesmo ano o laser foi utilizado pela primeira vez na Odontologia por Stern e Sognnaes Seu estabelecimento como terapêutica efetiva despertou interesses no seu efeito em tecidos vivos, principalmente após a publicação de alguns trabalhos com animais em 1968 (Ex. Taylor, Skear e Roeber), quando foram observados os efeitos do laser de cristal de rubi sob a mucosa oral ${ }^{1}$.

Inicialmente, o uso da tecnologia para tratamento dental tinha poucas indicações. Nos dias de hoje as possibilidades de uso têm aumentado e a utilização do laser tem se difundido em todas as diferentes áreas da Odonto$\log a^{5}$

Recentemente o interesse da pesquisa na área do laser de baixa potência tem crescido muito no que se refere aos seus efeitos sobre os diversos tecidos. Vários estudos vêm sendo realizados experimentalmente com a finalidade de observar os efeitos ultra-estruturais provocados nas células irradiadas com comprimentos de onda, doses e potência variados.

A laserterapia de baixa intensidade modula vários processos biológicos em modelos animais e em humanos, estimulando a cicatrização e síntese de colágeno, promovendo o processo de regeneração musculoesqueletal seguido de injúria, diminuindo a resposta inflamatória e elevando a neoformação de vasos sanguíneos ${ }^{6}$.

\section{Proliferação Celular}

Alguns estudos ${ }^{6,7}$ têm mostrado que a fototerapia é capaz de aumentar a proliferação de osteoblastos, estimular a osteogênese e, conseqüentemente acelerando a consolidação de fraturas.

Stein et al. ${ }^{6}$ avaliaram o efeito da laserterapia de $632,8 \mathrm{~nm}, 10 \mathrm{~mW}$ e doses de $0.14,0.43$ e $1.43 \mathrm{~J} / \mathrm{cm}^{2} \mathrm{em}$ osteoblastos humanos. Foi observado que o laser promoveu proliferação, diferenciação e maturação de osteoblastos in vitro quando comparado com células não irradiadas. Para os autores, essa habilidade do laser sugere que ele seja capaz de aumentar a reparação óssea em humanos.

Stein et al. ${ }^{7}$ verificaram que a laserterapia de baixa intensidade com $670 \mathrm{~nm}$ e doses de $1 \mathrm{~J} / \mathrm{cm}^{2}$ e $2 \mathrm{~J} / \mathrm{cm}^{2}$ teve um efeito bioestimulatório positivo no crescimento e diferenciação celular em osteoblastos humanos durante as primeiras $72 \mathrm{~h}$ após irradiação. Destaca-se ainda o fato de melhores resultados terem sido obtidos com dose de $1 \mathrm{~J} /$ $\mathrm{cm}^{2}$.

Numerosos estudos experimentais e clínicos 8,9 sugerem que a laserterapia modula processos metabólicos celulares, que leva a um aumento do potencial regenerativo dos tecidos biológicos. Recentemente, foi demonstrado que - laser aumenta a proliferação de células tronco mesenquimais e células cardíacas ${ }^{10}$; outros correlacionaram o aumento da cicatrização a maior expressão de procolágeno tipo I e III e a maior síntese de colágeno ${ }^{11}$.

Assim, a laserterapia mostra-se efetiva na promoção da proliferação de diferentes células. Eduardo et al. ${ }^{12}$ verificaram uma maior atividade proliferativa de células tronco da polpa dental humana submetidas a irradiação laser (InGaAIP) de 660nm e 20mW em relação ao controle não irradiado nas mesmas condições de nutrição. Enquanto que Kreisler et al. ${ }^{13}$ investigaram os efeitos da irradiação laser na proliferação de fibroblastos gengivais humanos. As células foram irradiadas com dose de 1.96$7.84 \mathrm{~J} / \mathrm{cm}^{2}$, usando um laser semicondutor de $809 \mathrm{~nm}$ e $10 \mathrm{~mW}$. O estudo concluiu que as células irradiadas revelaram uma atividade de proliferação consideravelmente alta após $24 \mathrm{~h}$ de irradiação.

Os lasers de baixa intensidade (não-cirúrgicos), em virtude das baixas densidades de energias e comprimentos de onda, são capazes de penetrar nos tecidos ${ }^{14}$. Muitos estudos têm demonstrado a sua utilização na reparação tecidual mais rápida e menos dolorosa em estomatite aftosa recorrente (afta), úlceras traumáticas, lesões herpéticas, pericoronarite, gengivite, queilite angular, pericementite, síndrome da ardência bucal, alveolite, disfunção temporomandibular (DTM) e mucosite ${ }^{15,16}$.

Tal atuação do laser sobre o processo de cicatrização é, de fato, um dos seus efeitos mais desafiadores. Seu desempenho é freqüentemente atribuído ao aumento da proliferação celular por mecanismos ainda não total- 
mente compreendidos ${ }^{17}$. É possível que o laser aumente a celularidade dos tecidos irradiados acelerando o ciclo mitótico, favorecendo a neovascularização e formação de tecido de granulação, cujos papeis são fundamentais na reparação tecidual ${ }^{3}$.

Quando a laserterapia é usada no espectro eletromagnético visível, existe uma fotobioestimulação inicial na mitocôndria, a qual ativa uma cadeia de eventos biológicos. Quando a irradiação é no espectro infravermelho, há estímulo dos canais da membrana plasmática, resultando em mudanças na permeabilidade da membrana, temperatura e gradiente de pressão. Tanto a luz visível e infravermelha pode ser absorvida por diferentes componentes da cadeia respiratória celular como os cromóforos na citocromo c oxidase ${ }^{18}$ ou porfirinas, a qual resulta na produção de espécies reativas de oxigênio ou radicais superóxido ${ }^{19}$.

Tem sido comentado que as espécies reativas de oxigênio têm um papel fundamental no aumento da proliferação de queratinócitos ${ }^{4}$.

As porfirinas são polipeptídios endógenos capazes de absorver melhor os comprimentos de ondas menores (de $360 \mathrm{~nm}$ ) quando comparados aos comprimentos de onda maiores (630nm) da luz laser ${ }^{20}$.

Após a fotorrecepção, em ambos os casos, existe transdução e amplificação de sinais, tendo como resposta subseqüente proliferação, diferenciação ou síntese de proteínas, incluindo fatores de crescimento celular que incrementam ainda mais o processo proliferativo ${ }^{19,21}$. A resposta biológica das células irradiadas com laser revela também uma alteração na atividade mitocondrial de oxidação redução, resultando em uma cascata de reações bioquími$\operatorname{cas}^{21}$.

Segundo Mognato et al. ${ }^{22}$ a reação de oxidação parece estar associada à estimulação e proliferação enquanto que a reação de redução parece estar associada com a inibição do crescimento celular.

Atividade Mitocondrial e Metabolismo Celular

A mitocôndria possui um importante papel em muitas condições fisiopatológicas, desde a homeostase do cálcio, geração de oxigênio e controle da apoptose. A avaliação da atividade mitocondrial em células submetidas à irradiação é um tópico de interesse ${ }^{23}$.

Pesquisas realizadas com lasers de baixa intensidade revelaram o aumento da funcionalidade mitocondrial, acarretando maior capacidade de regeneração e cicatrização dos tecidos, além de não provocar ação degenerativa nos espécimes irradiados ${ }^{18}$. Carnevalli et al. ${ }^{24}$ já haviam relatado que a laserterapia no espectro vermelho pode favorecer a formação de mitocôndrias gigantes, como também um aumento no número delas.

Foi observado por Carnevalli et al. ${ }^{24}$ que quando as células são irradiadas ocorre um intenso agrupamento de mitocôndrias na região perinuclear nas 24 e 48h após a irradiação. Visualizou-se ainda alterações na morfologia da mitocôndria de uma aparência filamentosa para granular nas $72 \mathrm{~h}$ após a proliferação, além da distribuição no citoplasma ser maior do que no grupo controle não irradiado. A concentração da mitocôndria na região perinuclear indica a necessidade de energia para síntese de proteína e duplicação do material genético. Nesse estudo, as células do grupo controle exibiram uma aparência filamentosa e ainda um pequeno número desta organela, o que indica segundo Bortoleto et al. ${ }^{23}$ baixa atividade mitocondrial.

$\mathrm{Na}$ realidade, o exato mecanismo que leva a uma taxa elevada de mitose não é completamente entendido, mas diferentes pesquisadores sugerem várias teorias para tentar explicar esse processo ${ }^{25}$. Como já citado, a ação da laserterapia é baseada na absorção de luz pelos tecidos, o que gera uma série de modificações no metabolismo celular.

Kreisler et al. ${ }^{4}$ enfatizam que ocorre uma estimulação de fotorreceptores na cadeia respiratória mitocondrial, a luz laser é absorvida, produzindo efeitos fotofísicos e fotoquímicos que, juntos ou isolados, estimulam a membrana mitocondrial, aumentando o potencial de membrana e, conseqüentemente mudando as propriedades ópticas das mitocôndrias. Esta mudança resulta num aumento da produção de oxigênio molecular e ATP, o qual estimula a atividade do DNA e RNA para síntese de proteínas reguladoras do ciclo celular e assim a velocidade de mitose pode ser aumentada26-28.

De acordo com Karu' ${ }^{29}$ a intensificação na síntese de DNA ocorre devido ao aumento do número de células que passam da fase $\mathrm{G} 1$ para fase $\mathrm{S}$, além de uma maior intensidade na síntese de DNA pelas células que se encontram na fase S. Destaca-se ainda o fato da percentagem de células em mitose não ser alterada durante as primeiras horas após a irradiação.

Hawkins-Evans, Abrahamse ${ }^{19}$ confirmaram que quando a célula é submetida à irradiação laser, observa-se um aumento na produção de ATP, maior atividade da enzima fosfatase alcalina, o que incrementa a proliferação celular, e ainda maior expressão de citocinas (interleucina 6) e danos ao DNA. Assim, foi sugerido que a irradiação laser tem um efeito terapêutico adicional por estimular a produção de citocinas, promovendo a comunicação célula-célula, migração e proliferação para auxiliar no processo de cicatrização natural.

De acordo com Stein et al. ${ }^{6}$ a laserterapia induz a fosforilação de proteínas quinases MAPK/ERK nas células, as quais sabe-se estar associadas ao mecanismo de proliferação celular.

Vale salientar que a interação da luz laser com os tecidos pode levar a diferentes resultados (estimulação ou inibição) dependendo de vários fatores, como comprimento de onda, dose, potência, tempo, número de irradiações, propriedades ópticas dos tecidos e tipo de célula irradiada, além das características fisiológicas das células no momento da irradiação $27,30,31$.

De acordo com Karu a luz laser estimula as células que estão crescendo pobremente no momento da 
irradiação. Então se o tecido é completamente funcional no momento da irradiação, não existe nada para a irradiação laser estimular e nenhum efeito terapêutico será observado, no entanto se o tecido está danificado, a irradiação laser tentará normalizar a função celular, restaurar a homeostase e estimular a cicatrização e reparo.

De fato, a magnitude da resposta celular a irradiação depende do estado fisiológico da célula. A irradiação é condicionada pela quantidade de nutrientes disponíveis e pela idade da cultura celular, por exemplo. Geralmente, células em fase exponencial de crescimento são mais fotossensíveis que àquelas na fase estacionária de crescimento ${ }^{26}$

\section{Laser e Atividade Mitótica}

Hawkins-Evans, Abrahamse ${ }^{19}$ relatam que o comprimento de onda interfere potencialmente na resposta celular. Os resultados de seu estudo indicaram que o laser de $632,8 \mathrm{~nm}$ resultou em efeito estimulatório mais efetivo do que $830 \mathrm{~nm}$ em fibroblastos humanos.

Lubart et al. ${ }^{20}$, verificaram que o número de mitoses aumentou em fibroblastos cultivados e irradiados com laser HeNe com comprimento de onda de 630nm quando comparados com os grupos controles não irradiados. O número de mitoses atingiu seu máximo quando a dose foi de $15 \mathrm{~J} / \mathrm{cm}^{2}$. A partir da dose de $60 \mathrm{~J} / \mathrm{cm}^{2}$ a quantidade de mitoses, quando comparado ao grupo controle, decaiu. O mesmo aconteceu para o grupo irradiado com $750 \mathrm{~nm}$. Entretanto, para o grupo irradiado com $360 \mathrm{~nm}$, o potencial mitótico máximo foi com a dose de 0,6 J/cm², decaindo já a partir de $1 \mathrm{~J} / \mathrm{cm}^{2}$. Os resultados destes autores indicam a existência de um limiar estimulatório, em um mesmo comprimento de onda, a partir do qual ocorre um efeito destrutivo sob o mecanismo de proliferação celular. Além disso, os diferentes comprimentos de onda utilizados mostraram efeitos biológicos diversos, sendo necessária menor dose para promover resultados destrutivos na célula, quando o comprimento de onda era menor.

De acordo com Karu ${ }^{26}$ o aumento da dose provoca um dano nos fotorreceptores e como resultado, o efeito biomodulatório do laser é reduzido. Então o aumento da dose causa uma destruição dos receptores, a qual é acompanhada por uma inibição do metabolismo e conseqüentemente morte celular.

Kreisler et al. ${ }^{4}$ reforçam a teoria quando afirmam que a irradiação laser com dose de $4 \mathrm{~J} / \mathrm{cm}^{2}$ tem efeito estimulatório, enquanto que doses muito altas de energia tem características inibitórias.

Mester et al. ${ }^{32}$ demonstraram que pequenas doses em períodos apropriados de tempo são mais efetivas do que quando administradas de uma só vez. O estudo identificou que a dose isolada de $5 \mathrm{~J} / \mathrm{cm}^{2}$ ou exposições múltiplas de $2.5 \mathrm{~J} / \mathrm{cm}^{2}$ com tempo adequado entre as exposições pode ser efetiva no tratamento de feridas em situações clínicas por acelerar a reparação. Essas aplicações estimularam a atividade mitocondrial, a migração e proli- feração de células, enquanto mantinham a viabilidade celular sem causar danos adicionais.

O efeito cumulativo de baixas doses (2,5 ou 5J/ $\mathrm{cm}^{2}$ ) determina um efeito estimulatório enquanto múltiplas exposições a altas doses $\left(10\right.$ e $\left.16 \mathrm{~J} / \mathrm{cm}^{2}\right)$ resultam em um efeito inibitório e são caracterizadas por uma diminuição na viabilidade e proliferação celular com uma quantidade significante de danos a membrana celular e ao DNA ${ }^{30}$.

\section{Laser e Células Tumorais}

A proliferação de células normais e tumorais pode ser estimulada, esse processo vai depender dos parâmetros da luz e da taxa de proliferação celular no momento da irradiação.

A proliferação celular de forma autônoma é uma das características mais marcantes de uma neoplasia maligna e esse processo colabora com a disseminação de clones celulares malignos. O uso da laserterapia durante esse processo neoplásico pode favorecer um aumento da proliferação e diferenciação celular, já que a mesma apresenta efeitos bioestimulatórios significantes.

Vários são os trabalhos realizados com a intenção de demonstrar a ação dos lasers de baixa potência na estimulação da proliferação celular de tumores, ou células residuais que estejam casualmente presentes durante a laserterapia de um determinado tecido.

A ação na atividade proliferativa é um tópico controvertido. A ação dos lasers tem sido encontrada em estudos de culturas celulares tanto inibindo, quanto proliferando ou mesmo sendo indiferentes quanto ao crescimento ${ }^{17,27}$

Com o objetivo de elucidar o mecanismo biológico da proliferação celular, Sroka et al. ${ }^{33}$ avaliaram o efeito da laserterapia em células de diferentes origens e diferentes graus de malignidade, comparando-as com células normais. Foi verificado um aumento do padrão mitótico em células benignas e malignas, após irradiação com doses no intervalo de 4 a $8 \mathrm{~J} / \mathrm{cm}^{2}$. No entanto foi observada uma redução na taxa de proliferação celular, quando a dose ultrapassava esse intervalo de energia independente do comprimento de onda.

Pinheiro et al. ${ }^{17}$ observaram no seu estudo in vitro um aumento significativo da proliferação de células malignas do carcinoma epidermóide de laringe, quando submetidas à irradiação laser de $670 \mathrm{~nm}$ de comprimento de onda com doses entre 0.04 e $4.8 \mathrm{~J} / \mathrm{cm}^{2}$. Afirmaram ainda que esse estímulo proliferativo teve relação direta com a dose, comprimento de onda e fisiologia do tecido irradiado.

Carnevalli et al. ${ }^{24}$ demonstraram que células cultivadas e irradiadas com laser de baixa intensidade (830 $\mathrm{nm}$ e $2 \mathrm{~J} / \mathrm{cm}^{2}$ ) exibiram maior síntese de ATP e capacidade mitótica se submetidas ao estresse nutricional quando comparadas com células não-irradiadas do grupo controle. Os autores sugerem que o laser de baixa intensidade seja capaz de estabilizar a homeostase metabólica por influenciar na morfologia e função mitocondrial e dos filamentos 
citoplasmáticos, tornando as células irradiadas morfologicamente e bioquimicamente mais estáveis. Além disso, as células não-irradiadas apresentaram maiores taxas de apoptose do que as irradiadas após o quarto dia do experimento.

Kreisler et al. ${ }^{4}$ ao irradiar células in vitro do carcinoma epidermóide de laringe humano, utilizando o laser diodo AsGaAl, potência de 10mW e doses de 1.96, 3.92, $7.84 \mathrm{~J} / \mathrm{cm}^{2}$, verificaram um considerável efeito estimulatório na proliferação das células irradiadas quando comparadas ao grupo controle não irradiado. Destacaram ainda que as doses tiveram um impacto similar na atividade proliferativa.

Outro estudo investigou o efeito de diferentes doses e comprimentos de onda de um laser diodo em duas linhagens de células humanas cancerosas: HeLa (células epiteliais do adenocarcinoma) e TK6 (Linfoblasto). Utilizouse laser diodo contínuo de 808nm, um pulsado com 905nm e de forma combinada (808nm + 905nm) no intervalo de doses de 1-60 $/ \mathrm{cm}^{2}$. O efeito bioestimulante da laserterapia na forma pulsada e combinada foi levemente superior àqueles que receberam a luz de forma isolada em células HeLa. Na proliferação de células TK6 não foi encontrado nenhum efeito significante. Para Mognato et al. ${ }^{22}$ os resultados desse estudo são uma confirmação de estudos prévios realizados em células humanas, onde apenas um aumento discreto na proliferação celular aparentou ser estimulado pela luz laser.

Werneck et al. ${ }^{27}$ realizaram um estudo a fim de avaliar a influência do tempo e do comprimento de onda em células malignas oriundas do carcinoma epidermóide de laringe. Os grupos de células irradiadas com o laser de $685 \mathrm{~nm}$ e $830 \mathrm{~nm}$ mostraram maior taxa de proliferação quando comparados ao grupo controle. Ademais, se observou diferenças entre os índices proliferativos quando se comparou diferentes tempos de irradiação no grupo de $685 \mathrm{~nm}$ de comprimento de onda.

Foi verificado no estudo de Castro et al. ${ }^{31}$ um efeito biomodulatório positivo na proliferação de células KB do carcinoma de soalho de boca submetidas à irradiação laser com $685 \mathrm{~nm}$ e $830 \mathrm{~nm}$, e dose de $4 \mathrm{~J} / \mathrm{cm} \square$. O grupo irradiado com 830nm teve um aumento da proliferação celular após 48h, o que não ocorreu nos grupos de $685 \mathrm{~nm}$ e grupo controle.

Renno et al. ${ }^{28}$ investigaram os efeitos da irradiação laser de 670, 780 e 830 nm na proliferação células provenientes do osteossarcoma humano. Nenhum efeito significante foi observado na proliferação de células do osteossarcoma após irradiação com laser de 830nm. Já quando utilizaram o comprimento de onda de 780nm houve um aumento significante na proliferação celular com doses de $1,5 \mathrm{~J} / \mathrm{cm}^{2}$ e $10 \mathrm{~J} / \mathrm{cm}^{2}$. Para o comprimento e onda de $670 \mathrm{~nm}$ houve um aumento significante na proliferação apenas com dose de $5 \mathrm{~J} / \mathrm{cm}^{2}$.

Nota-se que os efeitos da irradiação laser têm sido investigados em células malignas. Esta é uma importante linha de pesquisa a ser investigada, particularmente quando se considera a segurança e eficácia da laserterapia de baixa intensidade em pacientes oncológicos, nos casos em que o tratamento poderá ser impedido pela proximidade de um tumor existente ou a uma relevante história passada de câncer.

Dessa forma, enquanto não há evidências que a laserterapia tem um efeito carcinogênico, já existem evidências suficientes para sugerir que ela possui um efeito bioestimulatório nas células tumorais

\section{DISCUSSÃO}

A descoberta de tecnologias que inovem as ciências biológicas, principalmente no que se refere à Medicina e à Odontologia, tem sido fonte de inspiração para muitos trabalhos de pesquisa. O laser terapêutico (de baixa potência) tem aplicações recentes e pouco descritas na literatura e apesar de ser uma radiação não-ionizante, tem suas propriedades citotóxicas ainda desconhecidas.

Numerosos estudos experimentais in vitro já foram realizados $7,10,12,13,31,26,27,28$ concordando com a hipótese de que a laserterapia seja capaz de influenciar os processos metabólicos celulares, ao aumentar a proliferação de várias células, como os fibroblastos, osteoblastos, queratinócitos, células tronco e células oriundas de tumores malignos.

Existem várias teorias que tentam explicar o aumento do metabolismo celular promovido pela laserterapia via ativação cadeia respiratória ${ }^{3,4}$.

Uma possível teoria sustenta que a luz é absorvida por porfirinas e flavoproteínas (componentes da cadeia respiratória) gerando oxigênio singleto, o qual estimula a síntese de RNA e DNA ${ }^{4}$. Há um efeito benéfico na presença de pequenas quantidades destes radicais nos tecidos por ativar o mecanismo de mitose celular. Acredita-se que este mecanismo indutivo funcionaria até certa concentração de oxigênio singleto, dose esta que quando ultrapassada faria a célula entrar num processo destrutivo ${ }^{20}$.

Outra teoria diz que ocorre a fotoexcitação de cromóforos na molécula citocromo c oxidase, influenciando a propriedade redox da mitocôndria e conseqüentemente aumentando o fluxo de elétrons na molécula ${ }^{4}$. Uma revelação mais recente ${ }^{34}$ indica que a atividade da citicromo c oxidase é também regulada pelo óxido nítrico (NO). Sugere-se que o laser ative o fluxo de elétrons na citocromo c oxidase, revertendo a inibição da respiração mitocondrial pelo NO.

Acredita-se também que a luz do laser induz um aquecimento local transitório nos cromóforos, que pode causar alterações estruturais ou na atividade bioquímica das células ${ }^{25}$.

Essas reações primárias que ocorrem na mitocôndria estão conectadas com a síntese de RNA e DNA no núcleo, e ainda com alterações na membrana plasmática através das reações secundárias de sinalização celular ${ }^{34}$. 
As reações secundárias são mediadas por mensageiros, como as enzimas transmembranas ${ }^{34}$ que têm papel importante na regulação do $\mathrm{pH}$ intracelular, volume da célula, transporte de íons e proliferação celular. Atuam ainda como mensageiros secundários, o cálcio $\left(\mathrm{Ca}^{2+}\right)$, controlando a transcrição de genes e a proliferação celular ${ }^{35}$; as citocinas, proteínas quinases, espécies reativas de oxigênio e o $\mathrm{NO}^{6,19,25}$

Permanece ainda obscuro qual desses mecanismos é decisivo para desencadear a cascata de sinalização que culminará com o incremento da proliferação celular. Na realidade todos os mecanismos discutidos acima levam ao mesmo resultado: ativação da cadeia respiratória, aumento da produção de ATP, RNA e DNA. Entretanto, dependendo da dose utilizada e do estado fisiológico das células irradiadas alguns mecanismos prevalecem significantemente ${ }^{25}$. Isso explica porque a bioestimulação não é sempre possível.

Baseando-se no fato do laser, através desses mecanismos, possuir a capacidade de estimular a proliferação de células benignas, que possuem uma maior estabilidade genômica, é possível acreditar que células portadoras de anomalias genéticas neoplásicas, o laser contribua com o processo de crescimento neoplásico.

O efeito do laser terapêutico na cicatrização é o ponto chave desta revisão, pois sua capacidade de induzir a proliferação celular, ainda desconhecida, é tema de muitas controvérsias ${ }^{17,31}$. Se considerarmos que o laser terapêutico é capaz de inibir a apoptose, aumentar a produção de ATP $^{24}$ e de acelerar o ciclo celular por favorecer bioquimicamente e estruturalmente 27,36 a maquinaria de reprodução da célula; como avaliar, então, estes fenômenos atuando sobre uma célula neoplásica?

De fato em células benignas, após todo estímulo proporcionado ao processo metabólico, será obtida de forma satisfatória a cicatrização, como a reparação da mucosite em pacientes oncológicos, efeito da laserterapia já bastante consagrado na literatura ${ }^{16}$. Mas, em tecido maligno, o laser parece favorecer um maior substrato de células alteradas genomicamente $e^{4,17,22,33}$ acelerando indiretamente o ganho de mutações adicionais no processo natural da carcinogênese.

É possível que as células, genomicamente alteradas, ganhem atributos indesejáveis, tornando-se mais susceptíveis ao processo indutor proliferativo além de modificações progressivas do seu fenótipo, criando clones com maior capacidade para proliferação, indiferenciação e sobrevida.

A escassez de trabalhos sobre o tema na Odontologia é notável, principalmente, a falta de experimentos in vivo com a finalidade de observar esses efeitos proliferativos da luz laser em células malignas, os quais já foram observados por alguns pesquisadores em modelos in vitro ${ }^{17,27,31}$. O fato é que no modelo in vitro muitas variáveis que são encontradas no in vivo, são excluídas, como por exemplo, o sistema imune que influencia no processo da carcinogênese.
Nos trabalhos citados observa-se que a laserterapia ora estimula 4,17,27,31, ora inibe ${ }^{33}$ ou muitas vezes é indiferente no processo de proliferação celular ${ }^{22,28}$. Além disso, foi observado que cada linhagem celular responde diferentemente a comprimentos de onda e combinações de doses específicas ${ }^{28,31}$. Ou, dentro da mesma linhagem, apresentam resposta dependente do comprimento de onda e dose utilizados ${ }^{28}$.

A magnitude do efeito bioestimulante depende tanto do estado físico da célula ${ }^{3}$ quanto do limiar de quantidade da energia laser absorvido. Afirma-se que quando a dose ultrapassa esse limiar, o grau de atividade biológica celular também aumenta. Quando a dose aumenta demais, nenhum aumento na atividade celular pode ser observado, ou pode ser verificada ainda uma inibição da atividade $^{8}$.

É muito difícil, se não impossível, comparar os resultados experimentais com cultura de células obtidos pelos diversos pesquisadores. Alguns autores irradiam uma camada única de cultura celular, outros uma suspensão celular ${ }^{25,27}$, além disso, podem variar devido a diferentes manejos com as células, diferentes técnicas de laboratório e ainda, a irradiação com diferentes intervalos de dose. Então, o resultado final do experimento pode ser diferente.

Dessa forma, as diferenças fenotípicas e genotípicas das linhagens celulares, a falta de padronização das condições experimentais e as múltiplas combinações dos parâmetros da laserterapia, explicam os resultados divergentes que são obtidos quando se irradia células benignas e malignas com o laser terapêutico.

Acreditamos que a falta de padronização, controle de qualidade e o pobre desenho experimental contribuam para a produção de resultados negativos em alguns estudos e a censura de muitos resultados positivos. Uma característica dos estudos negativos pode ser o uso de doses muito baixas, técnicas de tratamento ineficientes ou conclusões inadequadas. Outra consideração importante é que o sucesso dos resultados in vitro nem sempre reproduz diretamente resultados positivos em aplicações in vivo, já que outras variáveis estão presentes neste último modelo.

Essa revisão e discussão só enfatizam a necessidade de mais estudos utilizando-se várias combinações de comprimentos de onda e doses em diferentes linhagens de células in vitro e in vivo, com a finalidade de padronizar os desenhos experimentais, tornando possível uma comparação dos resultados e conseqüentemente determinando os parâmetros da laserterapia que deverão ser utilizados para obtenção dos efeitos desejados.

\section{CONSIDERAÇÕES FINAIS}

Apesar dos relatos contraditórios sobre o efeito da luz laser na proliferação celular, estudos mostram que 
doses e comprimentos de onda apropriados da luz laser são terapeuticamente benéficos na reparação tecidual. Tem sido postulado por diversos autores que o efeito promovido pelo laser depende da dose aplicada, além disso, existe uma especificidade do tecido ao comprimento de onda. Dessa forma, são necessárias mais investigações para analisar os mecanismos fisiológicos responsáveis pela obtenção de resultados contrastantes quando se usa a irradiação laser em culturas de células normais e malignas. Para que a laserterapia seja utilizada como modalidade terapêutica confiável, é necessário utilizar adequadamente: dose, comprimento de onda e densidade de energia de acordo os efeitos e objetivos propostos para cada caso a ser tratado.

\section{A B S T R A C T}

Low energy laser has been used as an adjuvant therapy or as a therapeutic tool in many different areas of Dentistry. It is recognized by its anti-inflammatory and analgesic properties, and also as a tissue repair inductor. Low intensity laser property in stimulate cell proliferation during wound healing and its biomodulation mechanisms are discussed in this paper. These properties have already been established for cultured benign cells, but there is a controversy when extended to the spectrum of the malignant neoplastic process, normally generating great discussions. The objective of this work was to perform a literature review about the low intensity laser capacity in induce cell proliferation. The discussion is specially concerned about its effects on malignant cells.

Key words: Laser therapy. Cell proliferation. Laser therapy, low-level. Wound healing

\section{REFERÊNCIAS}

1. Sulewski JG. Historical survey of laser dentistry. Dent Clin North Am. 2000; 44(4):717-52.

2. Brugnera JR.A. Biomodulatory effect of lasertherapy-clinical indications. Dentistry Braz Dent J. 2004; 15(Suppl):60.

3. Karu T. Photobiology of low-power laser effects. Health Phys. 1989; 56(5):691-704

4. Kreisler M, Christoffers AB, Willershausen B, d'Hoedt B. Low-level $809 \mathrm{~nm}$ GaAlAs laser irradiation increases the proliferation rate of human laryngeal carcinoma cells in vitro. Lasers Med Sci. 2003; 18(2):100-3.

5. Sperr W. Laser supported dentistry. The way into future. Braz Dent J. 2004; 15(SI):56.

6. Stein A, Benayahu D, Maltz L, Oron U. Low-Level laser irradiation promotes proliferation and differentiation of human osteoblasts in vitro. Photomed Laser Surg. 2005; 23(2):161-6.

7. Stein E, Koehn J, Sutter W, Wendtlandt G, Wanschitz F, Thurnher $D$ et al. Initial effects of low-level laser therapy on growth and differentiation of human osteoblast-like cells. Wien Klin Wochenschr. 2008; 120(3-4):112-7.

8. Hawkins-Evans D, Abrahamse H. Effect of multiple exposures of low-level laser therapy on the cellular responses of wounded human skin fibroblasts. Photomed Laser Surg. 2006; 24(6):70514.

9. Eduardo FP, Mehnert DU, Monezi TA, Zezell DM, Schubert MM, Eduardo CP. Cultured epithelial cells response to phototherapy with low intensity laser. Lasers Surg Med. 2007; 39(4):365-72.

10. Tuby $H$, Maltz L, Oron U. Low-level laser irradiation promotes proliferation of mesenchymal and cardiac stem cells in culture. Lasers Surg Med. 2007; 39(4):373-8.

11. Saperia D, Glassberg E, Lyons AF, Abergel RP, Baneux P, Castel JC et al. Demonstration of elevated type I and type III procollagen mRNA levels in cutaneous wounds treated with Helium-Neon laser. Biochem Biophys Res Commun. 1986; 138(3):1123-8.

12. Eduardo FP, Bueno DF, Freitas PM, Marques MM, Passos-Bueno. Stem cell proliferation under low intensity laser irradiation: a preliminary study. Lasers Surg Med. 2008; 40(6):433-8.

13. Kreisler M, Christoffers AB, Al-Haj H, Willershausen B, d'Hoedt B. Low level $809 \mathrm{~nm}$ diodo laser induced in vitro stimulatin of the proliferation of human gingival fibroblasts. Lasers Surg Med. 2002; 30(5):365-9.
14. Genovese WJ. Laser de baixa intensidade. Aplicação em odontologia. São Paulo: Lovisa; 2000.

15. Catão MHCV. Os benefícios do laser de baixa intensidade na clínica odontológica na estomatologia. Rev Bras Patol Oral. 2004; 3(4):214-8

16. Kelner N, Castro JFL. Laser de baixa intensidade no tratamento da mucosite oral induzida pela radioterapia: relato de casos clínicos. Rev Bras Cancerol. 2007; 53(1):29-33.

17. Pinheiro AL, Carneiro NS, Vieira AL, Brugnera A Jr, Zanin FA, Barros RA, Silva PS. Effects of low-level laser therapy on malignant cells: In vitro study. J Clin Laser Med Surg. 2002; 20(1):23-6.

18. Karu TI, Kolyakov SF. Exact action spectra for cellular responses relevant to phototherapy. Photomed Laser Surg. 2005; 23(4):35561

19. Hawkins-Evans D, Abrahamse H. Efficacy of three laser wavelengths for in vitro wound healing. Photodermatol Photoimunol Photomed. 2008; 24(4):199-210.

20. Lubart R, Wollman $Y$, Friedmann H, Rochkind S, Laulicht I. Effects of visible and nearinfrared lasers on cell cultures. J Photochem Photobiol B Biol. 1992; 12(3):305-10.

21. Oliveira DAAP, Oliveira RF, Zangaro RA, Soares CP. Evaluation of low-level laser therapy of osteoblastic cell. Photomed Laser Surg. 2008; 26(4):401-4

22. Mognato M, Squizato F, Facchin F, Zaghetto L, Corti L. Cell growth modulation of human cells irradiated in vitro with Low-level laser therapy. Photomed Laser Surg. 2004; 22(6):523-6.

23. Bortoleto R, Silva NS, Zângaro RA, Pacheco MTT, Pacheco-Soares C. Mitocondrial membrane potential after low-power laser irradiation. Lasers Med Sci. 2004; 18(4):204-6.

24. Carnevalli CMM, Soares CP, Zângaro RA, Pinheiro ALB, Silva NS Laser light prevents apoptosis on Cho K-1 cell line. J Clin Laser Med Surg. 2003; 1(4):193-6.

25. Karu TI. Low-power laser therapy. In: Vo-Dinh T, editor. Biomedical photonics handbook. Boca Raton: CRC Press; 2003.

26. Karu TI. Photobiological fundamentals of low-power laser therapy. J Quantum Electron 1987; 23(10):1703-17.

27. Werneck CE, Pinheiro ALB, Pacheco MTT, Soares CP, Castro JLF. Laser light is capable of inducing proliferation of carcinoma cells in culture: A spectroscopic in vitro study. Photomed Laser Surg. 2005; 23 (3):300-3

28. Renno ACM, McDonnell PA, Parizotto NA, Laakso EL. The effects of laser irradiation on osteoblast and osteosarcoma cell proliferation and differentiation in vitro. Photomed Laser Surg. 2007; 25(4):27580 . 
29. Karu TI. Effects of visible radiation on cultured cells. Photochem Photobiol. 1990; 52(6):1089-98.

30. Karu TI. Molecular mechanisms of therapeutic effect of low intensity laser irradiation. Laser Life Sci. 1988; 2(1):53-74.

31. Castro JLF, Pinheiro ALB, Werneck CE, Soares CP. The effect of laser therapy on the proliferation of oral KB carcinoma cells: an in vitro study. Photomed Laser Surg. 2005; 23(6):586-9.

32. Mester $E$, Mester AE, Mester A. The biomedical effect of laser application. Lasers Surg Med. 1985; 5(1):31-9.

33. Sroka R, Schaffer M, Fuchs $C$, Pongratz $T$, Schrader-Reichard $U$, Busch $\mathrm{M}$ et al. Effects on the mitosis of normal and tumor cells induced by light treatment of different wavelengths. Lasers Surg Med. 1999; 25(3):263-71.

34. Karu TI, Pyatibrat LV, Kalendo GS. Photobiological modulation of cell attachment via cytochrome $\mathrm{c}$ oxidase. Photochem Photobio Sci. 2004; 3(2):211-6.

35. Manteifel VM, Karu TI. Structure of mitochondria and activity of their respiratory chain in successive generations of yeast cells exposed to He-Ne laser light. Biol Bull. 2005; 32(6):556-66.
36. Karu TI. Primary and secundary mechanisms of action of visible tonear IR radiation on cells. J Photochem Photobio B Biol. 1999; 49(1):1-17.

Recebido em 10/03/2009

Aceito para publicação em 05/05/2009

Conflito de interesse: nenhum

Fonte de financiamento: nenhuma

Como citar esse artigo:

Henriques ACG, Cazal C, Castro JFL. Ação da laserterapia no processo de proliferação e diferenciação celular: revisão da literatura. Rev Col Bras Cir. [periódico na Internet] 2010; 37(4). Disponível em URL: http:/ /www.scielo.br/rcbc

\section{Endereço para correspondência:}

Aguida Cristina Gomes Henriques

E-mail: aguidacgh@gmail.com 